\title{
EXPERIMENTAL STUDY OF DEMOTIVATORS AND MEMES PERCEPTION COMPLEXITY ${ }^{1}$
}

\author{
Aleksandra V. Gorbacheva \\ Pushkin State Russian Language Institute, Moscow, Russia \\ Alexandra A. Berlin Khenis \\ Pushkin State Russian Language Institute, Moscow, Russia
}

Alexandra N. Puchkova

Pushkin State Russian Language Institute, Moscow, Russia;

Institute of Higher Nervous Activity and Neurophysiology of the Russian Academy of Sciences, Moscow, Russia

\section{Mikhail A. Osadchiy}

Pushkin State Russian Language Institute, Moscow, Russia

\begin{abstract}
The article presents the results of a pilot study of the perception of the demotivator and meme genres. It was a part of an experimental study of psychophysiological and psycholinguistic features of perception and understanding of multimodal extremist texts. The aim of the study is to develop and test the hypothesis about the influence of genre on perception of multimodal texts. To test the hypothesis, we analyze the respondents' eye movement data from the main experimental study $(n=60 ; 31$ forensic linguists with anti-extremism practice, 29 nonexperts). Research methods were eye-tracking and quantitative data processing. The following statistically reliable $\vec{\sim}$ data were obtained: compared to memes, respondents looked at demotivators (1) for a longer time, made (2) shorter तิ fixations, (3) with more of them, and also made (4) faster and (5) shorter saccades. These parameters may indicate $<$ a denser scanning pattern of viewing demotivators compared to memes and greater cognitive expenditure in assessing the semantic content of demotivator texts. The results of the study suggest a connection between genre and the degree of multimodal texts perception complexity. This provides an opportunity for further research in this direction and, in the future, will enable the development of norms of cognitive load of judicial linguists who analyse multimodal extremist texts.

Key words: multimodal text, creolized text, meme, demotivator, Internet genre, eye-tracking, perception.

Citation. Gorbacheva A.V., Berlin Khenis A.A., Puchkova A.N., Osadchiy M.A. Experimental Study of Demotivators and Memes Perception Complexity. Vestnik Volgogradskogo gosudarstvennogo universiteta. Seriya 2. Yazykoznanie [Science Journal of Volgograd State University. Linguistics], 2021, vol. 20, no. 2, pp. 74-86. (in Russian). DOI: https://doi.org/10.15688/jvolsu2.2021.2.7

\section{СЛОЖНОСТЬ ВОСПРИЯТИЯ ДЕМОТИВАТОРОВ И МЕМОВ: ЭКСПЕРИМЕНТАЛЬНОЕ ИССЛЕДОВАНИЕ ${ }^{1}$}

\author{
Александра Вячеславовна Горбачева \\ Государственный институт русского языка им. А.С. Пушкина, г. Москва, Россия \\ Александра Алехандровна Берлин Хенис \\ Государственный институт русского языка им. А.С. Пушкина, г. Москва, Россия
}




\section{Александра Николаевна Пучкова}

Государственный институт русского языка им. А.С. Пушкина, г. Москва, Россия; Институт высшей нервной деятельности и нейрофизиологии РАН, г. Москва, Россия

\section{Михаил Андреевич Осадчий}

Государственный институт русского языка им. А.С. Пушкина, г. Москва, Россия

Аннотация. В статье представлены предварительные результаты пилотного исследования восприятия жанров демотиватора и мема, которое проводится в рамках экспериментального изучения психофизиологических и психолингвистических особенностей восприятия и понимания поликодовых текстов экстремистской направленности. Разработана гипотеза о влиянии жанра на восприятие и понимание поликодовых текстов (А.В. Горбачева, М.А. Осадчий). Для ее верификации анализируются данные о движениях глаз респондентов, полученные в ходе основного экспериментального исследования. Осуществлены айтрекинг и количественная обработка данных (А.А. Берлин Хенис, А.Н. Пучкова). Систематизированы следующие статистически достоверные данные: в сравнении с мемами респонденты рассматривают демотиваторы (1) более продолжительное время, делают (2) более короткие фиксации, (3) при их большем количестве, а также совершают (4) более быстрые и (5) короткие саккады. Эти параметры могут указывать на более плотный сканирующий паттерн просмотра демотиваторов в сравнении с мемами и большие когнитивные затраты при оценке смыслового содержания текстов демотиваторов (А.А. Берлин Хенис, А.В. Горбачева, А.Н. Пучкова, М.А. Осадчий). Результаты исследования позволяют предположить наличие связи между жанром и степенью сложности восприятия поликодовых текстов. Это обеспечивает возможность проведения дальнейших исследований в данном направлении и в перспективе позволит разработать нормы когнитивной нагрузки судебных лингвистов, анализирующих поликодовые тексты экстремистской направленности.

Ключевые слова: поликодовый текст, креолизованный текст, мем, демотиватор, интернет-жанр, айтрекинг, восприятие.

Цитирование. Горбачева А. В., Берлин Хенис А. А., Пучкова А. Н., Осадчий М. А. Сложность восприятия демотиваторов и мемов: экспериментальное исследование // Вестник Волгоградского государственного университета. Серия 2, Языкознание. - 2021. - Т. 20, № 2. - C. 74-86. - DOI: https://doi.org/10.15688/ jvolsu2.2021.2.7

\section{Введение}

Современные цифровые технологии, преобразовавшие едва ли не все сферы человеческой жизнедеятельности, трансформировали и текстовую реальность, в результате чего поликодовые тексты, включающие знаки различных семиотических систем, превратились в обыденную форму хранения и передачи информации. Это сделало поликодовые тексты частотными объектами судебной лингвистической экспертизы, что породило вопрос о создании методик их исследования в специальных целях.

Существующий общественный запрос на объективизацию экспертного анализа требует, чтобы в основе прикладных разработок в данной области лежали результаты фундаментальных научных исследований процессов восприятия и понимания поликодовых текстов. В рамках этого запроса, помимо разработки алгоритмов реконструкции целостного смыс- ла текста, необходимым направлением работы является составление рекомендаций по управлению когнитивными процессами при осуществлении экспертного задания, поскольку их адекватная регуляция напрямую влияет на логику и степень объективности исследования. Одной из серьезных проблем в данной области представляется работа в состоянии утомления внимания, которое, кроме снижения продуктивности, может провоцировать экспертные ошибки. Уменьшить риски, связанные с последствиями этого состояния, могут оценка и последующее нормирование когнитивной нагрузки экспертов.

Первым шагом к определению порогов утомления внимания при оценке поликодовых текстов и разработке соответствующих норм может стать исследование параметров глазодвигательной активности и влияющих на нее факторов, поскольку именно движения глаз являются внешним коррелятом процессов восприятия и понимания, обусловленных работой 


\section{РЕЧЕВЫЕ МЕХАНИЗМЫ И ЕДИНИЦЫ ТЕКСТОВОЙ КОММУНИКАЦИИ}

произвольного внимания. Ранее мы освещали результаты нашего экспериментального исследования восприятия и понимания поликодовых текстов, которые касаются влияния на параметры движений глаз факторов, связанных с личностью воспринимающего субъекта [Берлин Хенис, Пучкова, 2020; Горбачева и др., 2020]. Однако взаимодействие человека с текстом как объектом действительности предполагает, что у последнего имеются заданные характеристики, способные детерминировать восприятие текста наравне с особенностями самого интерпретатора. Это означает, что внешняя организация поликодового текста, характер использованных образов и/или их расположение, свойства знаков различной степени условности (индексальные, иконические, символьные знаки) - все это может в той или иной степени определять качество внимания при работе с поликодовыми текстами. В настоящей статье мы рассмотрим в качестве такого внешнего определителя жанр поликодового текста.

\section{Материал и методы}

Значительная часть жанровых исследований поликодовых текстов, в особенности выполненных российскими учеными, посвящена мемам и демотиваторам. В работах некоторых отечественных коллег можно встретить указание на то, что перцептивная сложность поликодовых текстов коррелирует с их жанровой принадлежностью. Так, мемы в связи с их минималистичной формой оцениваются как когнитивно легкий жанр, ориентированный на быстрое восприятие и простое понимание, в первую очередь внутри социальных групп [Зиновьева, 2015, с. 196; Канашина, 2017; 2018а, c. 127; Ягодкина, 2019; и др.]. Порой к таким выводам приходят авторы, которые изначально придерживались обратной точки зрения, мотивируемой тем, что мемы - это тексты с высоким сжатием информации, которые в силу обусловленности пресуппозицией требуют от реципиента существенных умственных усилий при интерпретации [Канашина, 2018б, c. 76]. В то же время, знакомясь с источниками, мы не обнаружили оценок сложности восприятия демотиваторов, и это подсказывает, что в настоящий момент данный признак, ве- роятно, не является для исследователей сколько-нибудь определенным. Тем не менее особенности мемов и демотиваторов достаточно хорошо описаны в литературе, и их сравнение позволит обосновать предположение о том, какой из этих жанров базово сложнее для восприятия и понимания.

Разработка гипотезы. Начинать такое сравнение следует с описания демотиваторов и мемов как самостоятельных жанров. Демотиваторы (demotivators, demotivationals) выделяются большинством ученых как полноценный жанр с собственной внешней организацией, характером информации и функциями [Бабина, 2017; Бабина, Иванова, 2016; Баслина, Ухова, 2014; Бугаева, 2011; Клочко, 2017; Крылов, Стексова, 2020; Лутовинова, 2016; Рабкина, Каменева, 2013; и др.], хотя наряду с этим, основываясь на характере передаваемой информации, некоторые отечественные и зарубежные лингвисты осмысляют их как разновидность мемов [Канашина, 2017; Максимова, 2019; Сонин, Мичурин, 2012; Щурина, 2014б; Milner, 2012; и др.]. Наиболее понятным и устойчивым жанровым признаком демотиваторов является графический шаблон. Исследователи выделяют следующие обязательные компоненты шаблона демотиватора:

- одночастное или многочастное изображение, помещенное в черную рамку [Бабина, 2017; Бугаева, 2011; Крылов, Стексова, 2020; Лутовинова, 2016; Щурина, 2014а], обычно занимающее бо́льшую часть площади экранного пространства, отведенного для текста;

- комментарий в виде надписи или надписей, выполненных белым шрифтом на черном фоне под изображением [Бугаева, 2011; Лутовинова, 2016; Рабкина, Каменева, 2013; Сонин, Мичурин, 2012; Щурина, 2014а]: верхний блок содержит слоган, выражающий основную идею комментария, и в русском варианте с целью выдвижения выполняется начиная с прописной или полностью прописными буквами [Бугаева, 2011; Лутовинова, 2016; Сонин, Мичурин, 2012; Рабкина, Каменева, 2013; Щурина, 2014а]; нижний блок заполняет надпись или надписи, которые выполняются строчными буквами и содержат пояснение или продолжение слогана [Бугаева, 2011; Лутовинова, 2016; Рабкина, Каменева, 2013; Сонин, 
Мичурин, 2012]. При реализации классического - полного - шаблона (рис. 1) представлены обе надписи [Дурынина, Казяба, 2013], но расширение круга пользователей шаблона «приводит к постепенной утрате изначального отношения между фрагментами текста» [Сонин, Мичурин, 2012], поэтому в усеченном варианте может быть дан любой из них, при этом высказывание осуществляет одну из двух или обе указанные смысловые функции.

В противоположность простоте определения характеристик графического шаблона, установление специфической коммуникативной иели демотиватора представляется нетривиальной задачей. Во-первых, коммуникативная цель этого жанра сконструирована и декларирована компанией - создателем демотиваторов «Despair» в виде лозунга: «Разрушать мечты суровой правдой жизни» («Crushing dreams with hard truths») [Рабкина, Каменева, 2013, с. 146] - и зафиксирована в самом его названии - демотивационный постер / плакат. Во-вторых, имеются результаты лингвистического анализа, которые показывают, что в спектр коммуникативных целей демотиватора попадают дискредитация социально одобряемых ценностей, критика сложившейся ситуации, комическое представление какого-либо фрагмента действительности, распространение вирусной информации, самопрезентация [Голиков, Калашникова, 2010], побуждение других участников коммуникации разделить точку зрения автора [Бабина, 2017]. В-третьих, данные опросов респондентов свидетельствуют, что демотиватор - это «картинка с умной мыслью; сарказм в картинке; постер, который отражает определенную идею. Полученные ответы подтверждают информативность демотиватора и желание респондента поделиться некоей идеей, близкой адресанту» [Крылов, Стексова, 2020, с. 57]. Обобщая вышеперечисленные факты, мы приходим к выводу, что демотиватор является в большей степени жанром, информирующим о субъективной точке зрения на кого- или что-либо, и, согласно мнению Ю.В. Крылова и Т.И. Стексовой, «создается или используется не ради вступления в контакт и проявления эмоций, а для выражения какойлибо философской мысли, идеи, созвучной автору / пользователю» [Крылов, Стексова, 2020, с. 56-57]. В пользу этого свидетельствует и отчетливое деление информации на диктумную и модусную части посредством использования рамки, «которая способствует появлению субъективно окрашенного содержания, семиотически соотносящего общественный и личный опыт» [Бабина, 2017, c. 43]. Благодаря такому распределению информационного содержания демотиватор успешен в качестве реплики-стимула, инициирующей коммуникацию в форме дискуссии на заданную тему, и мало адекватен в качестве реплики-реакции [Крылов, Стексова, 2020, c. 57].

Последняя особенность демотиватора, которую требуется учесть, чтобы сделать

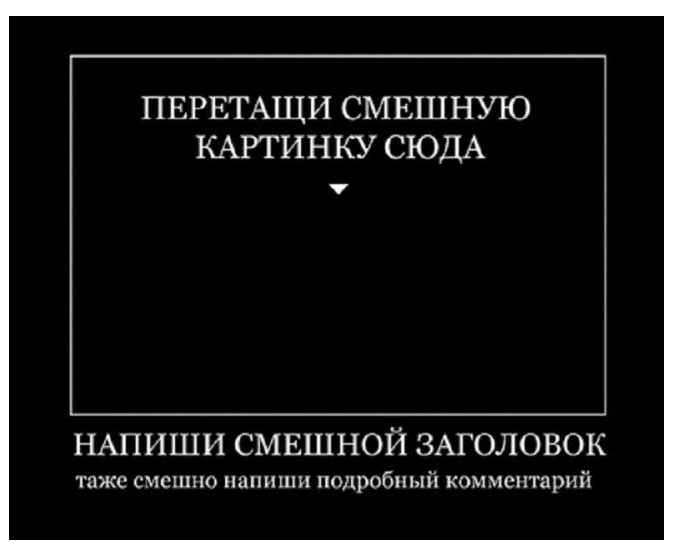

Рис. 1. Полный графический шаблон демотиватора

Fig. 1. Complete demotivator graphic template

Примечание. Источник: https://veralline.com/blog/open/3385.html\#! prettyPhoto. 


\section{РЕЧЕВЫЕ МЕХАНИЗМЫ И ЕДИНИЦЫ ТЕКСТОВОЙ КОММУНИКАЦИИ}

предположение о степени его перцептивной сложности, - преимущественная оригинальность контента в этом жанре. Несмотря на то что в ряде случае создатели демотиваторов опираются на различного рода прецеденты [Бугаева, 2011], к большей части информации авторы обращаются впервые, при подаче информации нередко прибегают к созданию эффекта неожиданности [Шурина, 2014а], а сама информация имеет характер известных и понятных обширному кругу лиц реалий.

Таким образом, демотиватор - это информационно оригинальный поликодовый жанр, информирующий о чьей-то личной точке зрения на что- или кого-либо, обладающий двухчастным графическим шаблоном, где гетерогенные части сообщения разграничены.

Описание жанровой специфики мема логично начинать с качества транслируемой информачии как наиболее устойчивого признака этого жанра. Мнения зарубежных и российских исследователей совпадают в том, что основное свойство информации, передаваемой посредством мемов, - это ее прецедентность и ориентированность на узнавание [Канашина, 2018а; Максимова, 2019; Никитина, Гудкова, Зандер, 2018; Пишкова, Смирнова, 2019; Щурина, 2014a; 2014б; Dancygier, Vandelanotte, 2017; Wiggins, Bowers, 2014]: возникновение мемов стадиально, и на каждой из стадий информация, служащая основой мема, становится известна все большему количеству людей и видоизменяется все существеннее [Wiggins, Bowers, 2014], в конце концов оказываясь оформленной при помощи шаблонов. Обязательность знаний о прецедентных именах, ситуациях, текстах, необходимых для понимания мема, вероятно, когнитивно облегчает этот жанр для целевых адресатов и усложняет для случайных (особенно в случаях локального характера мема) [Зиновьева, 2015; Пишкова, Смирнова, 2019]. При формировании гипотезы о перцептивной сложности текстов этого жанра также целесообразно учитывать серийность интернет-мемов, то есть, по словам С.В. Канашиной, способность образовывать ряды «родственных», схожих единиц, с общей тематикой, идеей и похожих по оформлению [Канашина, 2017]. В случае серийности обращение к определенной информации происходит чаще, а значит, доступ к соответствую- щим знаниям в памяти человека постепенно облегчается.

По данным опроса респондентов, проведенного Ю.В. Крыловым и Т.И. Стексовой, в коммуникации мем используется, «когда (он. - Примеч. авт.) смешной, чтобы разбавить ситуацию общения, разрядить; чтобы сократить время на описание состояние, эмоции; когда нужно выразить огорчение, негодование, разочарование, радость, степень любви к человеку или просто пошутить на какую-то тему; когда нужно быстро на что-то прореагировать» [Крылов, Стексова, 2020, с. 56]; «обычно в результате диалога, когда находится подходящий момент или просто случайно; когда он подходит к ситуации; в ироничных ситуациях...; мем в тему беседы» [Крылов, Стексова, 2020, c. 57]. Результаты экперимента свидетельствуют, что основной коммуникативной иелью мема, наряду с развлечением отправителя и получателя [Максимова, 2019], является выражение оценки чего-либо, эмоциональной реакции на что-либо, при этом такая эмоция, оценка уже известны адресату и представляют собой дискурсивную точку зрения в среде конкретной социальной группы [Крылов, Стексова, 2020; Сонин, Мичурин, 2012; Dancygier, Vandelanotte, 2017]. Это заключение подтверждается и фактом преобладания в меме модальной информации, выражаемой одновременно и изображением, и высказыванием [Канашина, 2016].

Наиболее сложным в определении жанровым признаком представляется устройство графического шаблона мема. Мы разделяем точку зрения С.А. Максимовой: «Жанровый состав виртуального дискурса очень подвижен: одни жанры приходят на смену другим, иногда "поглощая" уже существующие» [Максимова, 2019, с. 96]. Нынешние простые мемы представляют собой контаминацию двух ранних жанров - макроса (macro image, macros) и эдвайса (от англ. advice - «совет»); их графические шаблоны оказались настолько сходны, что пользователи из лингвокультур, в которые эти жанры были заимствованы, утеряли понимание связи между их формой и содержанием, в результате чего указанные жанры унифицировались и функционально [Сонин, Мичурин, 2012; Щурина, 2014a; Grundlingh, 2017; и др.]. Исследователи указывают на то, 
что внешняя организация простых мемов минималистична, «поскольку... сжатая форма... облегчает понимание, декодирование смысла мема интернет-пользователем» [Канашина, 2017, с. 87]. Обязательными частями шаблона простого мема (рис. 2) являются следующие компоненты:

- одночастное изображение, занимающее всю площадь мема; изображение может быть прецедентным и в этом случае выбирается из предложенных в рубрикаторе или авторским, что не исключает возможности апелляции к прецедентным персонажам или ситуациям [Канашина, 2017; Клочко, 2017; Щурина, 2014б];

- «надпись крупным шрифтом, как правило, белого цвета, вверху и/или внизу» изображения [Никитина, Гудкова, Зандер, 2018, c. 80]. Наиболее частотны мемы, где надпись имеет двухчастную структуру: первая часть выступает в качестве зачина (фрагмент или самостоятельное высказывание), вторая представляет собой панчлайн (от англ. punchline - «кульминация») - неожиданное остроумное завершение [Щурина, 20146, с. 88].

Таким образом, простой мем - это поликодовый жанр, информационно вторичный, выражающий эмоциональную оценку или реакцию на что- или кого-либо, обладающий двухчастным графическим шаблоном, где гетерогенные части сообщения условно не отделены друг от друга.

Сравнение характера информации, транслируемой в рамках рассмотренных жан- ров, позволяет выдвинуть в качестве гипотезы тезис о том, что демотиваторы когнитивно сложнее мемов: (1) информация в демотиваторах, в отличие от мемов, преимущественно первичная, отличается новизной, (2) адресата вынуждают анализировать показанную ситуацию, чтобы самостоятельно оценить справедливость точки зрения автора, вместо воспроизведения знакомой реакции, как в меме.

Респонденты и процедура эксперимента. Для проверки гипотезы мы проанализировали данные, собранные ранее в ходе лабораторного айтрекингового исследования восприятия и понимания поликодовых текстов экстремистского и неэкстремистского содержания. В эксперименте принимали участие респонденты $(n=60)$ с различной степенью информированности о фактах экстремистского дискурса: 31 лингвист-эксперт с опытом экспертиз по делам о противодействии экстремизму и 29 респондентов без экспертных компетенций. В качестве стимульного материала респондентам предъявлялись поликодовые тексты формата «статическое изображение + письменное высказывание». До начала эксперимента все участники были письменно предупреждены о целях проведения научного исследования и характере стимульного материала.

Анализируемые нами данные собраны в первой части эксперимента: респонденты просматривали стимул, после чего должны

\title{
Meme Top Text
}

\author{
Meme Photo
}

\section{Meme hottom text}

Рис. 2. Полный графический шаблон простого мема

Fig. 2. Complete graphic template of a simple meme

Примечание. Источник: https://podelki.pro/sdelat-mem-so-svoej-kartinkoj/. 


\section{РЕЧЕВЫЕ МЕХАНИЗМЫ И ЕДИНИЦЫ ТЕКСТОВОЙ КОММУНИКАЦИИ}

были оценить, является ли он экстремистским или нет (в случае затруднений респондент имел право ответить «затрудняюсь»), и прокомментировать смысловое содержание просмотренного стимула. Респонденты не были ограничены во времени просмотра стимула и обдумывания ответа. В ходе выполнения задания движения глаз респондентов регистрировались при помощи айтрекера EyeLink 1000+. Моменты начала и окончания просмотра стимула, а также принятия решения об оценке его содержания фиксировались автоматизированно.

Для проверки гипотезы о различной перцептивной сложности демотиваторов и мемов мы отобрали из имеющихся данных записи движений глаз респондентов в ответ на предъявление 6 демотиваторов и 7 мемов, организованных в соответствии с вышеописанными шаблонами жанров. Неравное число стимулов того и другого жанров объясняется тем, что дизайн эксперимента изначально не предполагал решения поставленной в этом исследовании задачи, в силу чего мы предлагаем считать его пилотным, а его результаты - предварительными.

Первичная обработка и чистка данных о движении глаз осуществлялись с помощью программного обеспечения «Data Viewer (SR research)». Анализ производился в программе «Statistica 10» и был условно разделен на два этапа. На первом этапе выполнялось сравнение глазодвигательной активности по жанрам, на втором этапе анализировались паттерны рассматривания изображений для каждого жанра.

\section{Результаты и обсуждение}

В качестве параметров движения глаз использовались длительность фиксаций, количество фиксаций, амплитуда саккад, время рассматривания (абсолютное и относительное) изображений или зон интереса.

Анализ времени рассматривания всех стимулов показал, что демотиваторы рассматривались значительно дольше мемов $(F(1,638)=20,9293, p<0,0001$, демотиваторы $11565,69 \pm 565,3$ мс, мемы $-8376,22 \pm 427,9$ мс).

В ходе анализа были обнаружены статистические различия в глазодвигательных параметрах при восприятии стимулов различ- ных жанров. Фиксации респондентов на мемах были более продолжительными в сравнении с фиксациями на демотиваторах $(F(1,23336)=10,2, p<0,001$, демотиваторы $267,26 \pm 1,02$ мс, мемы - 272,2 $\pm 1,17$ мс; см. рис. 2). Также обнаружены статистические различия в количестве фиксаций: большее количество фиксаций наблюдалось при рассматривании демотиваторов $(F(1,752)=$ $56,847, p<0,0001$, демотиваторы $-48,06 \pm 2,14$, мемы $-29,596 \pm 1,33)$. Значимое статистическое различие наблюдалось в амплитуде саккад. При рассматривании мемов делались более длинные амплитуды саккад в сравнении с демотиваторами $(F(1,23336)=13,624$, $p<0,0002$, демотиваторы $-3,44 \pm 0,076^{\circ}$, мемы $-3,88 \pm 0,093^{\circ}$ ).

Для проведения второго этапа анализа во всех стимулах были выделены зоны интереca - текстовые блоки или изобразительная часть стимула. Такой подход позволил сконструировать единый шаблон всех изображений внутри каждого жанра. Далее приведен анализ зрительных паттернов для стимулов каждого жанра по отдельности.

Анализ относительного времени рассматривания не показал статистической разницы между просмотром изображения и текста в демотиваторах. Однако здесь была установлена статистическая разница в некоторых глазодвигательных параметрах между текстовой и изобразительной зонами. На изображениях делалось больше фиксаций $(F(1,12546)=$ $461,52, p<0,0001$, изображение $-48,34 \pm 0,5$, текст $-36,652 \pm 0,287$ ), и они были более длительными в сравнении с текстовой зоной $(F(1,12546)=555,62, p<0,0001$, изображение $294,9 \pm 1,77$ мс, текст $-247,15 \pm 1,15$ мс). Также здесь были длиннее амплитуды саккад $(F(1,12546)=22,170, p<0,0001$, изображения $3,86 \pm 0,15^{\circ}$, текст $\left.-3,13 \pm 0,08^{\circ}\right)$.

При анализе мемов были выявлены статистически достоверные различия параметров движений глаз в изобразительной и текстовой зонах. Дополнительно была обнаружена разница в отдельных глазодвигательных параметрах при просмотре текста вверху и внизу.

Анализ относительного времени рассматривания зон показал статистически значимое преимущество в длительности просмотра изображения по сравнению с текстовыми 
зонами, при этом разницы между текстовыми зонами не обнаружено $(F(2,171)=263,49$, $p<0,0001$, изображение $-0,669 \pm 0,021$, текст сверху $-0,173 \pm 0,02$, текст снизу $0,147 \pm 0,01)$.

Зарегистрированы существенно более длительные фиксации на изображении в сравнении с двумя текстовыми зонами. Кроме того, в данном параметре текст вверху имел статистическое преимущество перед текстом внизу $(F(2,10566)=139,49, p<0,0001$, изображение $-292,83 \pm 1,94$ мс, текст вверху $262,72 \pm 1,95$ мс, текст внизу $-245,53 \pm 1,96$ мс; рис. 3). По сравнению с текстовыми зонами, на изображении было сделано большее количество фиксаций. В этом параметре также наблюдается статистически достоверное различие между текстом внизу и вверху $(F(2,10566)=426,04, p<0,0001$, изображение$28,58 \pm 0,33$, текст вверху $-23,092 \pm 0,4$, текст внизу - 13,29 $\pm 0,22)$. В сравнении с текстами, на изображениях присутствует наименьшая амплитуда саккад, при этом статистической разницы между текстовыми зонами не обнаружено $(F(2,10468)=225,56, p<0,0001$, изображение $-2,428 \pm 0,03^{\circ}$, текст вверху $3,47 \pm 0,045^{\circ}$, текст внизу $-3,32 \pm 0,052^{\circ}$ ).

Все средние показатели статистически значимо различаются.
Результаты исследования свидетельствуют о том, что стратегии рассматривания демотиваторов и мемов имеют отчетливые различия по показателям движения глаз: респонденты рассматривают демотиваторы (1) более продолжительное время, делая (2) более короткие фиксации, (3) при их большем количестве, а также совершая (4) более быстрые и (5) короткие саккады. В сравнении с мемами, перечисленные параметры могут указывать на более плотный сканирующий паттерн просмотра демотиваторов и бо́льшие затраты ресурсов внимания при оценке смыслового содержания демотиваторов. Одно из объяснений этому может состоять в разнице качества информации и распределения «смысловой нагрузки» у демотиватора и мема. Изредка исследователи обращают внимание на то, что отношения изображения и вербального текста в демотиваторе можно описать в терминах актуального членения, выделив в качестве темы изображение, а в качестве ремы - вербальную часть [Клочко, 2017, c. 69]. Важность изображения как источника информации об исходной ситуации, которую оценивает автор демотиватора в комментарии, относительная новизна содержания изображения могут оказывать влияние на параметры движения глаз при восприятии и понима-

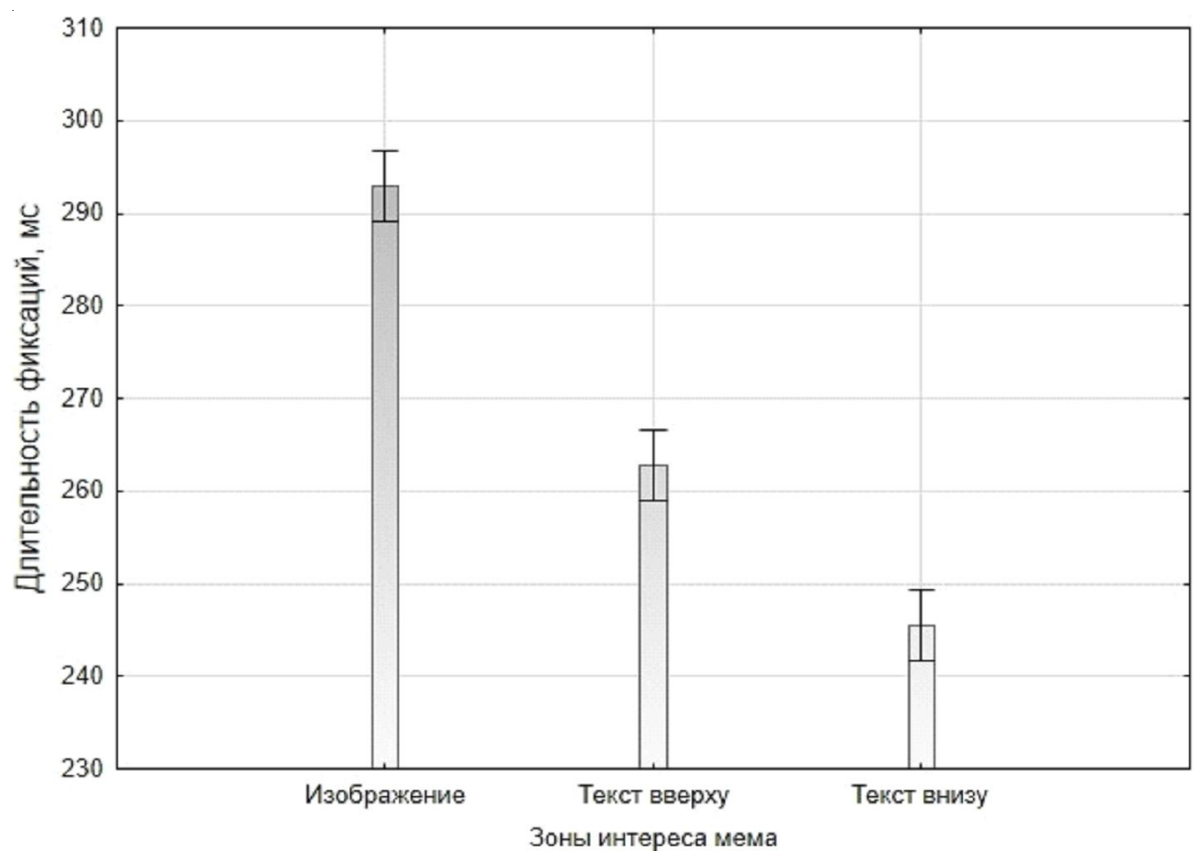

Рис. 3. Сравнение средней длительности фиксаций в различных зонах мемов

Fig. 3. Comparison of the average duration of fixations in different areas of interest of memes 


\section{РЕЧЕВЫЕ МЕХАНИЗМЫ И ЕДИНИЦЫ ТЕКСТОВОЙ КОММУНИКАЦИИ}

нии демотиваторов. Существует также вероятность того, что на паттерн рассматривания влияет количество информации, содержащейся в изображениях демотиваторов и мемов. Таким образом, предварительно можно говорить о том, что демотиваторы сложнее для восприятия и понимания, чем мемы.

Результаты анализа паттернов рассматривания демотиваторов и мемов обнаруживают и другую закономерность. При просмотре демотиваторов были зафиксированы более длительные, в большем количестве фиксации на изображениях, в то время как текст получал более быстрые и короткие саккады. Паттерны рассматривания мемов показали то же преимущество изображения над текстовыми блоками, как и в случае рассматривания демотиваторов. Данные свидетельствуют о том, что изображения, в сравнении с текстом, оказались более сложными для восприятия и распознавания. Такой результат для изображения вполне ожидаем и подтверждается многими исследованиями, посвященными поликодовым текстам [Петрова, Калугина, 2019а; 2019б; Риехакайнен, Петрова, 2018; Damaskinidis et al., 2017; Petrova, Riekhakaynen, 2019].

Значимые различия мы установили при анализе зрительного восприятия верхних и нижних текстовых блоков в мемах (см. рис. 3). При рассматривании верхнего текста, по сравнению с нижним, фиксации были более длительными и совершались в большем количестве, в то время как скорость и амплитуда саккад не имели статистических различий. Вероятно, на распознавание верхнего текста участникам требовалось больше времени, что в совокупности с большим количеством фиксаций может свидетельствовать о затрудненном восприятии верхнего текста по сравнению с нижним. Возможное объяснение этих затруднений состоит в том, что текст в меме имеет стандартное актуальное членение: в начальном фрагменте высказывания содержится повторяемая информация, которая является знакомой и требует того, чтобы ее вспоминали, а не запоминали. Вероятно, извлечение исходной информации из темы, сопряженное с ее вспоминанием, в действительности является для адресата более сложной, ресурсоемкой операцией, чем приращение информации из ремы, что соотно- сится с представлениями о возрастающей сложности понимания информации в связи с убыванием ее эксплицитности.

\section{Выводы}

Предварительные результаты, полученные в настоящем пилотном исследовании, подтверждают выдвинутую нами гипотезу о том, что демотиваторы являются более сложными для восприятия и понимания текстами, нежели мемы: зафиксированы такие характеристики движений глаз, которые указывают на более плотный сканирующий паттерн просмотра демотиваторов по сравнению с мемами. Опираясь на полученные результаты, мы можем обоснованно предполагать, что жанровая принадлежность коррелирует со степенью перцептивной сложности поликодового текста. Вместе с тем следует принять во внимание некоторые ограничения, которые пока не позволяют нам сделать категорический вывод: данные собраны в ходе эксперимента, процедура которого разрабатывалась в соответствии с другими исследовательскими целями; стимульный материал не нормализован по количеству единиц информации (пропозиций); не контролировалось влияние фактора экстремистского содержания стимула, обнаруженное на более ранних этапах исследований; не выравнивалось соотношение экстремистских и неэкстремистских стимулов. Дальнейшее направление исследования перцептивной сложности поликодовых жанров предполагает устранение текущих ограничений и проведение отдельного эксперимента для проверки сформулированной гипотезы, что в перспективе способно обеспечить разработку инструментов нормирования когнитивной нагрузки судебных экспертов-лингвистов, исследующих поликодовые материалы дел о противодействии экстремизму и терроризму.

\section{ПРИМЕЧАНИЕ}

${ }^{1}$ Работа выполнена при финансовой поддержке РФФИ, проект № 17-29-09170 «Исследование психофизиологических и психолингвистических особенностей восприятия и декодирования поликодовых текстов экстремистской направленности». 
The Reported Study Was Funded by RFBR, Project no. 17-29-09170 "Psychophysical and Psycholinguistic Assessment of Perception and Decoding of Multimodal Texts of Extremist Nature".

\section{СПИСОК ЛИТЕРАТУРЫ}

Бабина Л. В., 2017. Конфликт через призму демотиватора: интерпретационный аспект // Актуальные проблемы филологии и педагогической лингвистики. № 1. С. 41-46.

Бабина Л. В., Иванова А. С., 2016. Концептуальная интеграция как механизм интерпретации демотиватора // Вестник Тамбовского университета. Серия: Филологические науки и культурология. № 4 (8). С. 5-11.

Баслина, Е. Ю., Ухова Л. В., 2014. Демотивационный постер как речевой жанр сетевого юмоpa // Ярославский педагогический вестник. № 1, т. 1 : Гуманитарные науки. С. 135-140.

Берлин Хенис А. А., Пучкова А. Н., 2020. Оценка восприятия поликодовых текстов экстремистской направленности с применением метода айтрекинга // Международный аспирантский вестник. Русский язык за рубежом. № 1. С. 76-79.

Бугаева И. В., 2011. Демотиваторы как новый жанр в интернет-коммуникации: жанровые признаки, функции, структура, стилистика // Style: International Scientific and Scholarly Journal for Linguistics and Literary Stylistics. № 10. C. 147-158.

Голиков А. С., Калашникова А. А., 2010. Демотиваторы в интернет-коммуникации: генезис, смысл, типология // Вестник Харьковского государственного университета. Вып. 16. С. 124-130.

Горбачева А. В., Берлин Хенис А. А., Пучкова А. Н., Осадчий М. А., 2020. Современное состояние разработок в области методики судебно-лингвистического анализа поликодовых текстов: «Друзья, меняйте методичку» // Семиотико-семасиологическое измерение политического дискурса. М. : ИРЯ им. А. С. Пушкина. С. 290-308.

Дурынина Н. В., Казяба В. В., 2013. Структура вербальной составляющей демотиваторов англоязычной интернет-коммуникации // Международный научно-исследовательский журнал. № 10-2 (17). С. 109-110.

Зиновьева Н. А., 2015. Воздействие мемов на интернет-пользователей: типология интернетмемов // Вестник экономики, права и социологии. № 1. С. 195-201.

Канашина С. В., 2016. Текстовые категории модальности и темпоральности в интернет-меме как образец современного креолизованного текста // Вестник Рязанского государственного университета имени С.А. Есенина. № 1 (50). C. 79-87.

Канашина С. В., 2017. Что такое интернет-мем? // Научные ведомости Белгородского государственного университета. Серия: Гуманитарные науки. № 28 (277). С. 84-90.

Канашина С. В., 2018а. Интернет-мем и прецедентный феномен // Вестник Томского государственного педагогического университета. № 4 (193). C. 122-126. DOI: 10.23951/1609-624X2018-4-122-127.

Канашина С. В., 2018б. Семантические особенности интернет-мема как полимодального дискурса // Вестник Московского государственного лингвистического университета. Гуманитарные науки. № 16 (811). С. 74-80.

Клочко К. А., 2017. О реализации структуры «топик - комментарий» в поликодовом тексте // Евразийский гуманитарный журнал. № 2. C. 67-73.

Крылов Ю. В., Стексова Т. И., 2020. Новые жанры интернет-коммуникации (на примере демотиватора и мема) // Жанры речи. № 1 (25). С. 53-61.

Лутовинова О. В., 2016. Демотиватор как вид сетевого творчества // Вестник Волгоградского государственного университета. Серия 2, Языкознание. Т. 15, № 3. С. 28-36. DOI: https:// doi.org/10.15688/jvolsu2.2016.3.3.

Максимова С. А., 2019. Новостной мем как интернет-жанр // Вестник Томского государственного педагогического университета. № 5 (202). C. 95-101.

Никитина О. А., Гудкова О. А., Зандер Ф., 2018. Интернет-мем как мультимодальный феномен немецкоязычного интернет-дискурса // Язык и культура. № 43. С. 74-87. DOI: 10.17223/ 19996195/43/5.

Петрова Т. Е., Калугина Н. В., 2019а. Инфографика как способ снятия неоднозначности на занятиях по русскому языку как иностранному // Мир без границ: русский язык как иностранный в международном образовательном пространстве : материалы Междунар. науч.-практ. конф. (Псков, 13-14 дек. 2018 г.). Псков : Псков. гос. ун-т. С. 250-255.

Петрова Т. Е., Калугина Н. В., 2019б. Особенности движений глаз при чтении поликодовых текстов на русском языке // Когнитивные исследования языка. № 37. С. 825-830.

Пишкова Е. Ю., Смирнова М. С., 2019. Интернетмемы: коммуникативный и транслатологический аспекты // Известия Волгоградского государственного педагогического университета. Филологические науки. № 3 (136). С. $180-187$. 
Рабкина Н. В., Каменева В. А., 2013. Функциональный и прагматический потенциал демотиваторов как визуально-вербальной формы современной интернет-коммуникации // Политическая лингвистика. № 1 (43). С. 144-151.

Риехакайнен Е. И., Петрова Т. Е., 2018. Processing of Verbal and Non-Verbal Patterns: An EyeTracking Study of Russian // Advances in Intelligent and Soft Computing. № 797. C. 269276. DOI: 10.1007/978-981-13-1165-9 24.

Сонин А. Г., Мичурин Д. С., 2012. Эволюция поликодовых текстов: от воздействия к взаимодействию // Вопросы психолингвистики. № 16. C. 164-173.

Щурина Ю. В., 2014а. Интернет-мемы в структуре комических речевых жанров // Жанры речи. № 1/2 (9/10). С. 147-153.

Щурина Ю. В., 2014б. Интернет-мемы: проблема типологии // Вестник Череповецкого государственного университета. № 6 (59). С. 85-89.

Ягодкина М. В., 2019. Мемы в интернет-коммуникации // Art logos. № 2 (7). С. 142-151.

Damaskinidis G., Kourdis E., Zantides E., Sykioti E., 2017. Eye-Tracking the Semiotic Effects of Layout on Viewing Print Advertisements // Public Journal of Semiotics. № 8 (1). P. 46-66.

Dancygier B., Vandelanotte L., 2017. Internet Memes as Multimodal Constructions // Cognitive Linguistics. № 28 (3). P. 565-598. DOI:10.1515/ cog-2017-0074.

Grundlingh L., 2017. Memes as Speech Acts // Social Semiotics. № 28 (2). P. 1-22. DOI:10.1080/ 10350330.2017.1303020.

Milner R. M., 2012. The World Made Meme: Discourse and Identity in Participatory Media: PhD diss. Lawrence : University of Kansas. 321 p.

Petrova T. E., Riekhakaynen E. I., 2019. Eye-Tracking Study of Processing Russian Polycode Texts $/ /$ The $20^{\text {th }}$ European Conference on Eye Movements, ECEM 2019 (Alicante, Spain, 18-22 August 2019) : Abstract book. [S. 1. : s. n.]. P. 292.

Wiggins B. E., Bowers G. B., 2014. Memes as Genre: A Structurational Analysis of the Memescape // New Media \& Society. № 1 (21). P. 1-21. DOI: $10.1177 / 1461444814535194$.

\section{REFERENCES}

Babina L.V., 2017. Konflikt cherez prizmu demotivatora: interpretatsionnyy aspekt [Conflict through the prism of a demotivator: an interpretative perspective]. Aktualnye problemy filologii $i$ pedagogicheskoy lingvistiki [Current problems of philology and pedagogical linguistics], no. 1, pp. 41-46.
Babina L.V., Ivanova A.S., 2016. Kontseptualnaya integratsiya kak mekhanizm interpretatsii demotivatora [Conceptual integration as a mechanism of demotivator interpretation]. Vestnik Tambovskogo universiteta. Seriya: Filologicheskie nauki i kulturologiya [Vestnik of Tambov University. Philological and Cultural Studies Series], no. 4(8), pp. 5-11.

Baslina E.Yu., Uhova L.V., 2014. Demotivatsionnyy poster kak rechevoy zhanr setevogo yumora [A Demotivational Poster as a Speech Genre of Network Humour]. Yaroslavskiy pedagogicheskiy vestnik [Yaroslavl Pedagogical Newsletter], no. 1, vol. 1,pp. 135-140.

Berlin Khenis A.A., Puchkova A.N., 2020. Otsenka vospriyatiya polikodovykh tekstov ekstremistskoy napravlennosti s primeneniem metoda aytrekinga [An eye tracking study of extremist multimodal texts perception]. Mezhdunarodnyy aspirantskiy vestnik. Russkiy yazyk za rubezhom [Russian Language Abroad], no. 1, pp. 76-79.

Bugaeva I.V., 2011. Demotivatory kak novyy zhanr v internet-komunikatsii: zhanrovye priznaki, funktsii, struktura, stilistika [Demotivators as a new genre in Internet communications: genre signs, functions, structure]. Style: International Scientific and Scholarly Journal for Linguistics and Literary Stylistics, no. 10, pp. 147-158.

Golikov A.S., Kalashnikova A.A., 2010. Demotivatory $\mathrm{v}$ internet-kommunikacii: genezis, smysl, tipologija [Demotivators in Internet communication: genesis, meaning, typology]. Vestnik Harkovskogo gosudarstvennogo universiteta [Bulletin of Kharkov State University], no. 16, pp. 124-130.

Gorbacheva A.V., Berlin Khenis A.A., Puchkova A.N., Osadchiy M.A., 2020. Sovremennoe sostoyanie razrabotok v oblasti metodiki sudebnolingvisticheskogo analiza polikodovykh tekstov: «Druzya, menyayte metodichku» [Current state of development in the field of forensic linguistic analysis of multimodal texts: "Friends, change the manual"]. Semiotiko-semasiologicheskoe izmerenie politicheskogo diskursa [SemioticSemasiological Dimension of Political Discourse: A Collective Monograph], Moscow, Pushkin State Russian Language Institute, pp. 290-308.

Durynina N.V., Kazjaba V.V., 2013. Struktura verbalnoy sostavlyayushchey demotivatorov angloyazychnoy internet-kommunikatsii [Verbal part structure of demotivators of English-speaking Internet-communication]. Mezhdunarodnyy nauchno-issledovatelskiy zhurnal [International Scientific and Research Journal], no. 10-2 (17), pp. 109-110. 
Zinovieva N.A., 2015. Vozdeystvie memov na Internetpolzovateley: tipologiya Internet-memov [Impact of Memes on Internet Users: Typology of Internet-memes]. Vestnik ekonomiki, prava $i$ sociologii [Bulletin of Economics, Law, and Sociology], no. 1, pp. 195-201.

Kanashina S.V., 2016. Tekstovye kategorii modalnosti i temporalnosti $\mathrm{v}$ internet-meme kak obrazets sovremennogo kreolizovannogo teksta [Text categories of modality and temporality in an internet meme as a creolized text]. Vestnik Ryazanskogo gosudarstvennogo universiteta imeni A.S. Esenina [Bulletin of Ryazan State University named after A.S. Yesenin], no. 1 (50), pp. 79-87.

Kanashina S.V., 2017. Chto takoe internet mem? [What is an Internet meme?]. Nauchnye vedomost belgorodskogo gosudarstvennogo universiteta. Seriya: Gumanitarnye nauki [Scientific journal of Belgorod State University. Series: Humanities], no. 28 (277), pp. 84-90.

Kanashina S.V., 2018a. Internet-memi precedentnyj fenomen [Internet meme and precedent phenomenon]. Vestnik Tomskogo gosudarstvennogo pedagogicheskogo universiteta [Tomsk State Pedagogical University Bulletin], no. 4(193),pp. 122-126.DOI: 10.23951/1609624X-2018-4122-127.

Kanashina S.V., 2018b. Semanticheskie osobennosti internetmema kakpolimodalnogo diskursa [Semantic aspects of internet meme as multimodal discourse]. Vestnik Moskovskogo gosudarstvennogo lingvisticheskogo universiteta. Gumanitarnye nauki [Vestnik of Moscow State Linguistic University. Humanities], no. $16(811)$, pp. 7480 .

Klochko K.A., 2017. O realizatsii struktury «topik kommentariy» v polikodovom tekste [On the realization of the "topic-commentary" structure in a polycode text]. Evraziyskiy gumanitarnyy zhurnal [Eurasian Humanities Journal], no. 2, pp. 67-73.

Krylov Yu.V., Steksova T.I., 2020. Novye zhanry internet-kommunikatsii (na primere demotivatora i mema) [New Genres of Internet Communication (based on Demotivators and Memes)]. Zhanry rechi [Speech Genres], no. 1 (25), pp. 53-61.

Lutovinova O.V., 2016. Demotivator kak vid setevogo tvorchestva [Demotivational poster as a type of online creative work]. Vestnik Volgogradskogo gosudarstvennogo universiteta. Seria 2. Yazykoznanie [Science Journal of Volgograd State University. Linguistics], vol. 15, no. 3, pp. 28-36. DOI: https://doi.org/10.15688/ jvolsu2.2016.3.3.

Maksimova S.A., 2019. Novostnoymem kak internet-zhanr [News Meme as Internet Genre]. Vestnik Tomskogo gosudarstvennogo pedagogicheskogo universiteta [Tomsk State Pedagogical University Bulletin], no. 5 (202), pp. 95-101.
Nikitina O.A., Gudkova O.A., Zander F., 2018. Internet-mem kak multimodalnyy fenomen nemetskoyazychnogo internet-diskursa [Internet Meme as a Multimodal Phenomenon of the German Internet-Discourse]. Yazyk $i$ kultura [Language and Culture], no. 43, pp. 74-87. DOI: 10.17223/19996195/43/5.

Petrova T.E., Kalugina N.V., 2019a. Infografika kak sposob snyatiya neodnoznachnosti na zanyatiyakh po russkomu yazyku kak inostrannomu [Infographics as a way to remove ambiguity in Russian as a foreign language classes]. Mir bez granic: russkiy yazyk kak inostrannyy $v$ mezhdunarodnom obrazovatelnom prostranstve: materialy Mezhdunar. nauch.-prakt. konf. (Pskov, 13-14 dek. 2018 g.) [World without Borders: Russian as a Foreign Language in the International Educational Space. Materials of the International Scientific-Practical Conference(Pskov, 13-14 December 2018)], Pskov, Pskovskiy gosudarstvennyy universitet, pp. 250-255.

Petrova T.E., Kalugina N.V., 2019b. Osobennosti dvizheniy glaz pri chtenii polikodovykh tekstov na russkom yazyke [Peculiarities of eye movements when reading multicode texts in Russian]. Kognitivnye issledovaniya yazyka [Cognitive Studies of Language], no. 37, pp. 825-830.

Pishkova E.J., Smirnova M.S., 2019. Internet-memy: kommunikativnyy i translatologicheskiy aspekty [Internet memes: communicative and translatological aspects]. Izvestiya Volgogradskogo gosudarstvennogo pedagogicheskogo universiteta. Filologicheskie nauki [Ivzestia of the Volgograd State PedagogicalUniversity. Philological Sciences], no. 3(136), pp. 180-187.

Rabkina N.V., Kameneva V.A., 2013. Funktsionalnyy i pragmaticheskiy potentsial demotivatorov kak vizualno-verbalnoy formy sovremennoy internet-kommunikatsii [The functional and pragmatic potential of demotivators as a visualverbal form of modern internet communication]. Politicheskajya lingvistika [Political Linguistics], no. 1 (43), pp. 144-151.

Riekhakaynen E.I., Petrova T.E., 2018. Processing of Verbal and Non-verbal Patterns: An EyeTracking Study of Russian. Advances in Intelligent and Soft Computing, no. 797, pp. 269276. DOI: 10.1007/978-981-13-1165-9_24.

Sonin A.G., Michurin D.S., 2012. Evoljutsiya polikodovykh tekstov: ot vozdeystviya $\mathrm{k}$ vzaimodeystviyu [Evolution of multimodal text: impact to interaction]. Voprosy psikholingvistiki [Psycholinguistic Issues], no. 16, pp. 164-173.

Shchurina Yu.V., 2014a. Internet-memy v strukture komicheskikh rechevykh zhanrov [Internet memes in the structure of comic speech genres]. Zhanry rechi [Speech Genres], no. 1/2(9/10), pp. 147-153. 


\section{РЕЧЕВЫЕ МЕХАНИЗМЫ И ЕДИНИЦЫ ТЕКСТОВОЙ КОММУНИКАЦИИ}

Shchurina Yu.V., 2014b. Internet-memy: problema tipologii [Internet memes: the problem of typology]. Vestnik Cherepoveckogo gosudarstvennogo universiteta [Bulletin of Cherepovets State University], no. 6(59), pp. 85-89.

Yagodkina M.V., 2019. Memy v internet-kommunikatsii [Memes in Internet communications]. Art logos, no. 2 (7), pp. 142-151.

Damaskinidis G., Kourdis E., Zantides E., Sykioti E., 2017. Eye-tracking the semiotic effects of layout on viewing print advertisements. Public Journal of Semiotics, no. 8 (1), pp. 46-66.

Dancygier B., Vandelanotte L., 2017. Internet memes as multimodal constructions. Cognitive Linguistics, no. 28(3), pp. 565-598. DOI:10.1515/cog-2017-0074.
Grundlingh L., 2017. Memes as speech acts. Social Semiotics, no. 28 (2), pp. 1-22. DOI:10.1080/ 10350330.2017.1303020.

Milner R.M., 2012. The World Made Meme: Discourse and Identity in Participatory Media. PhD diss. Lawrence, University of Kansas. 321 p.

Petrova T.E., Riekhakaynen E.I, 2019. Eye-tracking study of processing Russian polycode texts. The $20^{\text {th }}$ European Conference on Eye Movements, ECEM 2019 (Alicante, Spain, 18-22 August 2019). Abstract book. S. 1., s. n., p. 292.

Wiggins B.E., Bowers G.B., 2014. Memes as genre: A structurational analysis of the memescape. New Media \& Society, no. 1 (21), pp. 1-21. DOI: $10.1177 / 1461444814535194$.

\section{Information About the Authors}

Aleksandra V. Gorbacheva, Researcher, Laboratory of Language and Cognition, Pushkin State Russian Language Institute, Akademika Volgina St, 6, 117485 Moscow, Russia, avgorbacheva@pushkin.institute, https://orcid.org/0000-0002-8906-3870

Alexandra A. Berlin Khenis, Specialist, Laboratory of Language and Cognition, Pushkin State Russian Language Institute, Akademika Volgina St, 6, 117485 Moscow, Russia, alexa.munxen@gmail.com, https://orcid.org/0000-0003-2034-1526

Alexandra N. Puchkova, Candidate of Sciences (Biology), Leading Researcher, Laboratory of Language and Cognition, Pushkin State Russian Language Institute, Akademika Volgina St, 6, 117485 Moscow, Russia; Senior Researcher, Laboratory of Neurobiology of Sleep and Wake, Institute of Higher Nervous Activity and Neurophysiology of the Russian Academy of Sciences, Butlerova St, 5a, 117485 Moscow, Russia, puchkovaan@gmail.com, https://orcid.org/0000-0002-2292-6475

Mikhail A. Osadchiy, Doctor of Sciences (Philology), Professor, Department of General and Russian Linguistics, Vice-Rector for Science, Pushkin State Russian Language Institute, Akademika Volgina St, 6, 117485 Moscow, Russia, maosadchiy@pushkin.institute, https://orcid.org/0000-0001-7964-9029

\section{Информация об авторах}

Александра Вячеславовна Горбачева, научный сотрудник лаборатории когнитивных и лингвистических исследований, Государственный институт русского языка им. А.С. Пушкина, ул. Академика Волгина, 6, 117485 г. Москва, Россия, avgorbacheva@pushkin.institute, https://orcid.org/0000-0002-8906-3870

Александра Алехандровна Берлин Хенис, специалист лаборатории когнитивных и лингвистических исследований, Государственный институт русского языка им. А.С. Пушкина, ул. Академика Волгина, 6, 117485 г. Москва, Россия, alexa.munxen@gmail.com, https://orcid.org/0000-0003-2034-1526

Александра Николаевна Пучкова, кандидат биологических наук, ведущий научный сотрудник лаборатории когнитивных и лингвистических исследований, Государственный институт русского языка им. А.С. Пушкина, ул. Академика Волгина, 6, 117485 г. Москва, Россия; старший научный сотрудник лаборатории нейробиологии сна и бодрствования, Институт высшей нервной деятельности и нейрофизиологии РАН, ул. Бутлерова, 5a, 117485 г. Москва, Россия, puchkovaan@gmail.com, https://orcid.org/0000-0002-2292-6475

Михаил Андреевич Осадчий, доктор филологических наук, профессор кафедры общего и русского языкознания, проректор по науке, Государственный институт русского языка им. А.С. Пушкина, ул. Академика Волгина, 6, 117485 г. Москва, Россия, maosadchiy@pushkin.institute, https://orcid.org/0000-0001-7964-9029 